Simposium I Jaringan Perguruan Tinggi untuk Pembangunan Infrastruktur Indonesia, 2016

\title{
Pengembangan Infrastruktur Bandar Udara menuju Bandar Udara Masa Depan dengan Konsep Airport City: \\ (Studi Kasus: Bandar Udara Internasional Sultan Hasanuddin)
}

\author{
Sakti Adji Adisasmita ${ }^{a}$, Suharman Hamzah ${ }^{\mathrm{a}}$, M. Isran Ramli ${ }^{\mathrm{a}}$, Muh. Asdar ${ }^{\mathrm{a}}$, Sakka Pati ${ }^{\mathrm{a}}$ \\ aniversitas Hasanuddin, Jl. Perintis Kemerdekaan km. 10 Tamalanrea, Makassar 90245, Indonesia
}

\begin{abstract}
Abstrak
Transportasi udara sebagai salah satu sub sektor transportasi yang termuda telah menunjukkan perkembangan yang demikian pesat. Kemajuan di bidang penerbangan telah merubah wajah dan peta perkembangan perekonomian, mobilitas penduduk, dan pembangunan secara luas. Untuk itu pembangunan bandar udara harus direncanakan kapasitasnya agar mampu melayani kegiatan penerbangan dalam jangka panjang, hal ini berarti melakukan perencanaan ke depan.

Perencanaan pembangunan bandar udara idealnya berkapasitas besar, yang diharapkan mampu melayani kegiatan lalu lintas pergerakan pesawat udara dan penumpang yang cenderung meningkat cepat dalam jangka panjang, namun kendala yang dihadapi adalah dana pembangunan yang dibutuhkan terbatas jumlahnya dan ruang wilayah untuk pembangunan yang tersedia adalah terbatas. Meskipun terdapat keterbatasan, namun pelayanan kepada penumpang harus ditingkatkan kualitasnya. Untuk mengantisipasi pertumbuhan jumlah penumpang, pesawat dan kargo maka perlu diantisipasi pengembangan bandar udara dan fasilitas komersialnya dengan Konsep Pengembangan Airport City.

Tujuan dari studi ini adalah : (1) mengidentifikasi faktor-faktor penting yang jadi isu utama dalam pengembangan Airport City secara umum dan Sultan Hasanuddin Airport City secara khusus, (2) Privatisasi dalam sub sektor transportasi udara/bandar udara telah dilakukan oleh banyak negara, tetapi mengapa di Indonesia belum satu pun bandar udara yang berhasil dalam penerapannya; bagaimana peluang, tantangan dan hambatannya, dan (3) untuk mendorong masuknya investor berinvestasi, faktor-faktor apa yang menjadi prasyarat dan langkah-langkah yang harus ditempuh.

Formula yang digunakan dalam mengantisipasi lonjakan pertumbuhan jumlah penumpang, pesawat dan kargo adalah dengan menggunakan model regresi. Model batasan kawasan kebisingan (BKK) dan kawasan keselamatan operasi penerbangan (KKOP) digunakan dalam pengembangan bandar udara yang terintegrasi dengan tata ruang wilayahnya (pengembangan bandar udara menuju Airport City).

Sebagai kata kunci dapat disebutkan bahwa: (1) dunia penerbangan dan bandar udara ke depan menjadi pusat pengembangan ekonomi dan bisnis yang kompetititf, (2) fasilitas komersial dengan cepat menghubungkan dengan pasar (markets), (4) perdagangan (air commerce) terhubung dengan airport city, dan (5) airport sebagai penggerak utama bisnis dan pengembangan kota di abad 21 ini $\left(21^{\text {st }}\right.$ century $)$.
\end{abstract}

Keywords: Transportasi Udara, Infrastruktur Bandar Udara, Airport City

\section{Latar Belakang}

Transportasi udara (penerbangan) sebagai salah satu sub sektor transportasi yang termuda telah menunjukkan perkembangan yang pesat (the youngest but the fastest). Kemajuan di bidang penerbangan telah merubah wajah dan peta perkembangan perekonomian, mobilitas penduduk, dan pembangunan secara luas. Untuk itu pembangunan bandar udara harus direncanakan kapasitasnya agar mampu melayani kegiatan penerbangan dalam jangka panjang, hal ini berarti melakukan perencanaan ke depan [1][2][3].

Perencanaan pembangunan bandar udara idealnya berkapasitas besar, yang diharapkan mampu melayani kegiatan lalu lintas pergerakan pesawat udara dan penumpang yang cenderung meningkat cepat dalam jangka panjang, namun kendala yang dihadapi adalah dana pembangunan yang dibutuhkan terbatas jumlahnya dan ruang wilayah untuk pembangunan yang tersedia adalah terbatas. Meskipun terdapat keterbatasan, namun pelayanan kepada penumpang harus ditingkatkan kualitasnya. Untuk mengantisipasi pertumbuhan jumlah penumpang, pesawat dan kargo maka perlu diantisipasi pengembangan bandar udara dan fasilitas komersialnya [1][2][3].

Bandar udara biasanya dibangun dengan jarak yang agak jauh dari pusat kota dengan tujuan untuk menghindari kebisingan, kemacetan dan sebagai antisipasi kemungkinan perluasan, tetapi bandar udara saat ini

\footnotetext{
* Corresponding author. Tel.: +62

E-mail address: muhisran@yahoo.com
} 
telah menjadi daya tarik tersendiri tidak hanya bagi bisnis tetapi juga untuk masyarakat, bandara menjadi pendorong utama lokasi bisnis, pembangunan perkotaan dan daya saing masyarakat dan merupakan mesin penggerak ekonomi yang sangat kuat dan kompleks dengan berbagai jenis layanan yang akan menimbulkan kebutuhan dan keberhasilan suatu bandar udara, sehingga bandar udara ke depan dikembangkan dengan konsep Airport City [1][2][3] [4].

\section{Konsep Airport City (Airport City Concept)}

Konsep "Airport City" telah efektif diadopsi oleh banyak bandara terbaik di dunia dan terbukti menjadi instrumen jitu yang dapat meningkatkan pelayanan kepada pelanggan. Konsep ini pada dasarnya merupakan konsep pengembangan bandara yang terpadu dengan pengembangan kawasan di sekitarnya dan meningkatkan standar pelayanan yang dapat meningkatkan pendapatan operator bandara [5][6]. Secara skematik konsep Airport City dapat dilihat pada Gambar 1.

\section{Airport City \& Aerotropolis Schematic}
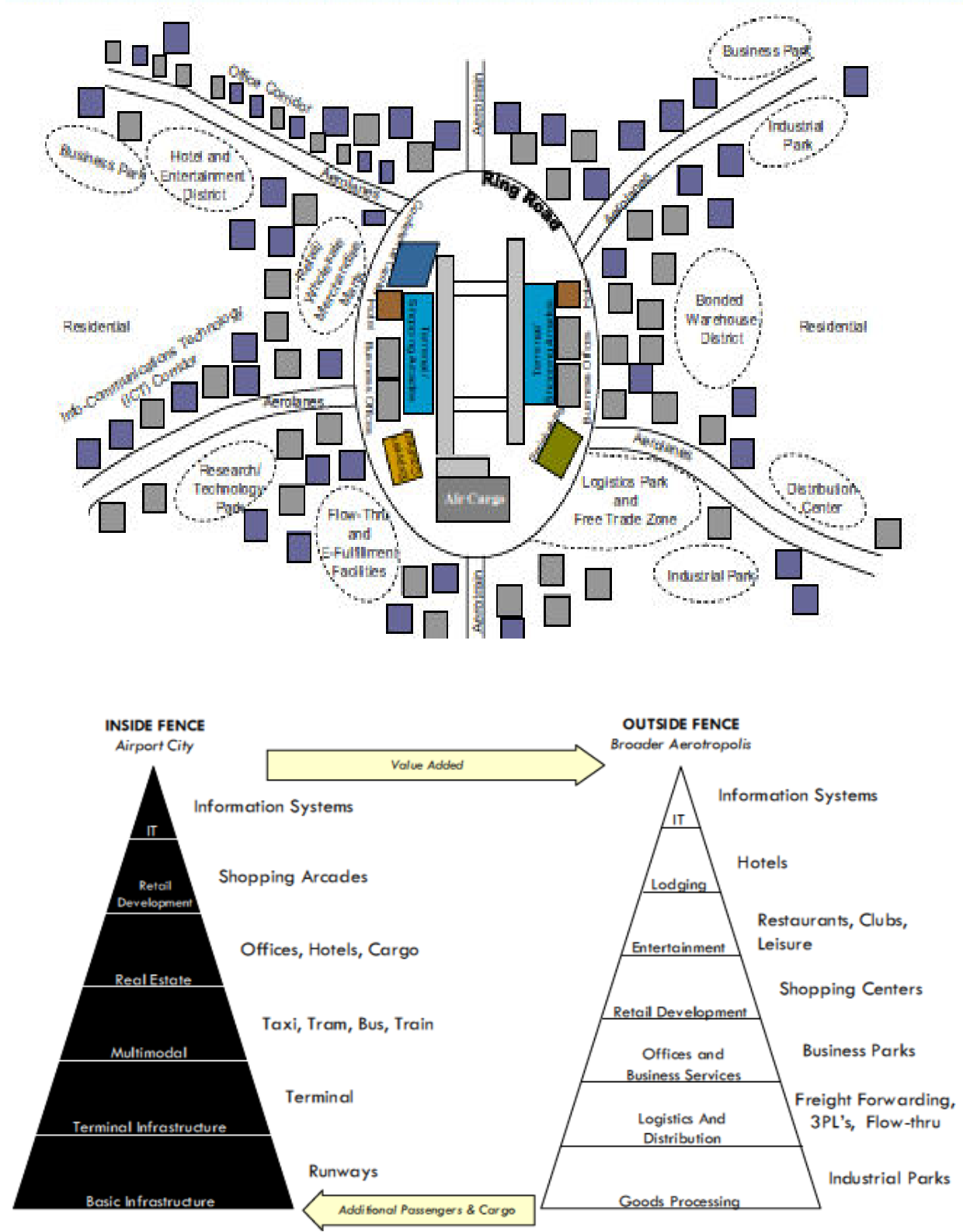

Gambar 1 (a) dan (b) Konsep Airport City (Airport City Concept)

Sumber: New Urban Development at and around Airports [6] 
Bandar udara dengan konsep Airport City sudah melebihi dari sekedar infrastruktur penerbangan, sudah menjadi multi moda, multi fungsi, membangkitkan pengembangan fasilitas komersial (commercial facilities) didalam dan disekitar bandar udara. Fungsinya sebagai pusat kota metropolitan (Airport City) yang terhubung dengan shopping mall, retail, restoran, leisure (fitnes, rekreasi, sinema), logistics dan air cargo pada sisi udara (airside) yang menyatu dengan terminal penumpang (passenger termminal). Pada sisi darat (landside) terhubung dengan pusat bisnis (business parks, logistics parks, industrial parks, wholesale merchandise marts, information and communications technology complexes, hotels and entertainment centers, office and retail centers, convention and exhibition centers, free trade zones, large mixed-use residential developments) dengan jangkauan area sampai $20 \mathrm{~km}$ dari bandar udara (Aerotropolis Airport) [5][6].

Beberapa bandar udara menghasilkan prosentase pendapatan yang lebih besar dari sumber non-aeronautical dari pada sumber aeronautical-nya, sehingga pengembangan fasilitas didalam dan disekitar bandar udara menjadikan pusat bangkitan dan tarikan pertumbuhan kota. Bandar udara mampu menampung tenaga kerja yang signifikan, menjadi pusat destinasi bisnis, perdagangan dan perbelanjaan.

\section{Metodologi}

Studi kasus pada penelitian ini adalah pada bandar udara internasional Sultan Hasanuddin, Makassar. Data yang dikumpulkan adalah data sekunder yang dikumpulkan melalui studi literatur, website bandar udara, diskusi, Dinas Tata Ruang, PT. Angkasa Pura 1, Biro Pusat Statistik, dan dinas terkait lainnya.

Formula yang digunakan adalah dengan model Regresi [7], BKK (Batasan Kawasan Kebisingan) dan KKOP (Kawasan Keselamatan Operasi Penerbangan)[2].

\section{Bandar Udara Internasional Sultan Hasanuddin Menuju Pusat Airport City di Indonesia}

Bandar Udara Internasional Sultan Hasanuddin Makassar adalah bandar udara termewah di Kawasan Timur Indonesia (KTI), namun kapasitasnya tak mampu lagi mengimbangi pertumbuhan volume penumpang setiap tahunnya. Bandar udara yang terletak sebagian besar lahannya di Kabupaten Maros berkapasitas 7,5 juta penumpang per tahun, saat ini melayani 9,3 juta penumpang, 88.553 pesawat dan 68.828 ton kargo. Perkembangan jumlah pertumbuhan penumpang, pesawat, dan kargo ditampilkan dalam Tabel 1, dimana pergerakan jumlah penumpang, pesawat dan kargo dari tahun 2010 - 2015 mengalami peningkatan yang cukup signifikan, kecuali pada tahun 2014 dikarenakan ada beberapa maskapai penerbangan menutup rutenya. Sementara rute Penerbangan dari/ke Bandar Udara Internasional Sultan Hasanuddin yang terdiri dari rute penerbangan domestik ada 34 rute dan rute internasional ke Singapura, Kula Lumpur dan Jeddah [8][9], yang dapat dilihat pada Gambar 2.

Tabel 1 Pergerakan Penumpang, Pesawat, dan Kargo, 2010 - 2015

\begin{tabular}{llll}
\hline Tahun & Penumpang & Pesawat & Kargo \\
\hline 2010 & 6.546 .942 & 64.940 & 54.623 .753 \\
2011 & 7.455 .408 & 73.077 & 57.628 .146 \\
2012 & 8.594 .339 & 82.870 & 65.179 .923 \\
2013 & 9.645 .386 & 94.759 & 69.682 .966 \\
2014 & 8.828 .586 & 83.348 & 66.555 .881 \\
2015 & 9.302 .437 & 88.553 & 68.828 .691 \\
\hline
\end{tabular}

Sumber: PT. Angkasa Pura 1 


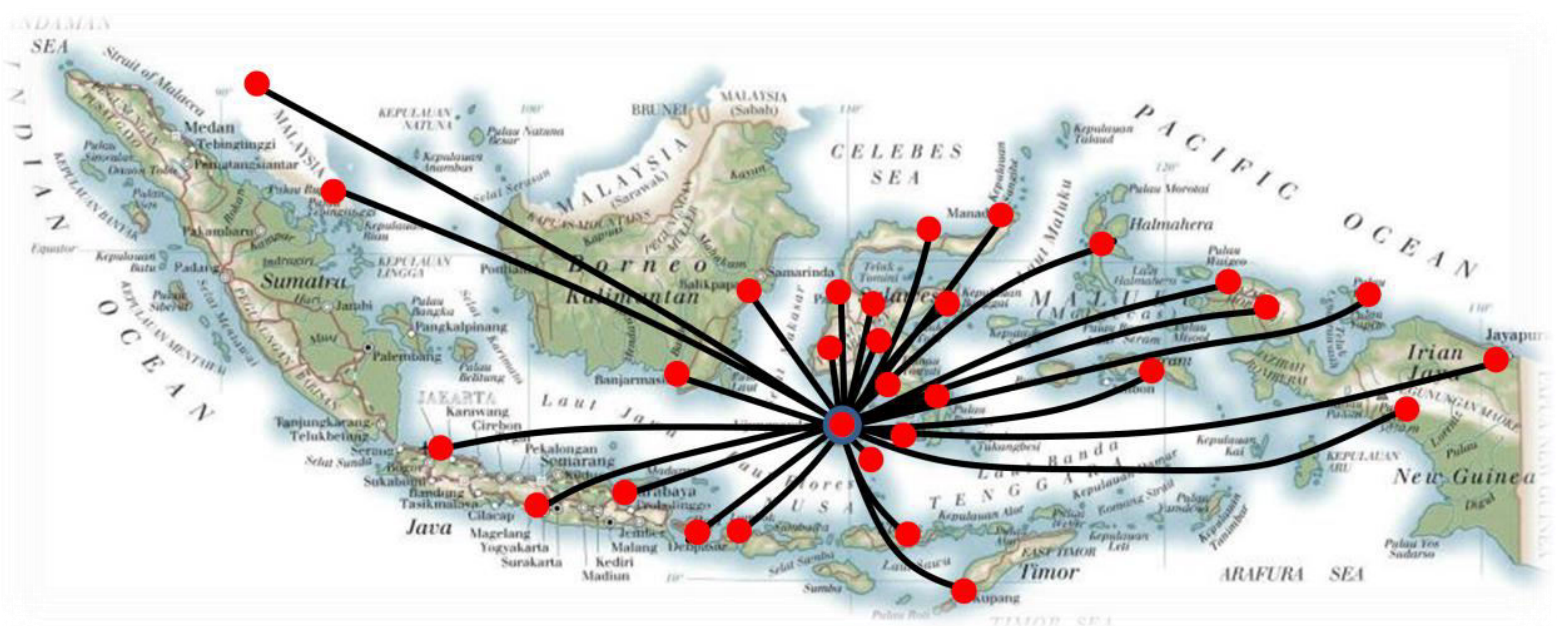

Gambar 2 Rute Penerbangan dari/ke Bandar Udara Internasional Sultan Hasanuddin Sumber: PT. Angkasa Pura 1

Pendapatan Bandar Udara Internasional Sultan Hasanuddin pada tahun 2015 adalah sebesar 307.330.743 milyar, dimana pendapatan aero sebesar 203.222.940 milyar (66 \%) dan non-aero sebesar 104.107.803 milyar (34\%). Sebagai perbandingan dengan pendapatan aero dan non-aero secara nasional adalah $76 \%$ dan $24 \%$ [8] dan pendapatan aero dan non-aero beberapa bandar udara lain dapat dilihat pada tabel berikut.

Tabel 2 Pendapatan Aero dan Non-Aero Beberapa Bandar Udara

\begin{tabular}{lll}
\hline Bandar Udara & Aero (\%) & Non-Aero (\%) \\
\hline Sultan Hasanuddin & 66 & 34 \\
Kuala Lumpur & 50 & 50 \\
Incheon & 35 & 65 \\
Dallas & 35 & 65 \\
\hline
\end{tabular}

Sumber: PT. Angkasa Pura 1 dan Website Bandar Udara

Oleh karena Bandar Udara Internasional Sultan Hasanuddin saat ini sudah menghadapi kendala kapasitas dan pendapatan non-aero (34\%) masih lebih kecil dibandingkan dengan pendapatan aero (66\%), maka untuk mengatasi kendala kapasitas dan memperbesar pendapatan non-aero, akan dikembangkan infrastruktur bandar udara baik sisi udara (airside), sisi darat (landside) maupun fasilitas komersialnya dengan konsep Airport City, dimana phase pengembangannya akan dilakukan dalam 4 tahapan. Ke 4 tahapan tersebut dapat dilihat pada Tabel 3 .

Tabel 3 Tahapan Pengembangan Infrastruktur Bandar Udara Internasional Sultan Hasanuddin

\begin{tabular}{|c|c|c|c|c|c|}
\hline \multicolumn{2}{|c|}{ Bandar Udara Internasional Sultan Hasanuddin } & Tahap I (2019) & Tahap II (2024) & Tahap III (2034) & Tahap IV (2044) \\
\hline \multicolumn{6}{|c|}{ Terminal } \\
\hline a. & Domestik & $126.684 \mathrm{~m}^{2}$ & $159.377 \mathrm{~m}^{2}$ & $196.022 \mathrm{~m}^{2}$ & $233.603 \mathrm{~m}^{2}$ \\
\hline & Internasional & $17.800 \mathrm{~m}^{2}$ & $44.187 \mathrm{~m}^{2}$ & $65.702 \mathrm{~m}^{2}$ & $85.322 \mathrm{~m}^{2}$ \\
\hline & Total & $144.484 \mathrm{~m}^{2}$ & $203.564 \mathrm{~m}^{2}$ & $261.724 \mathrm{~m}^{2}$ & $318.925 \mathrm{~m}^{2}$ \\
\hline \multicolumn{6}{|c|}{ Parkir Apron } \\
\hline \multicolumn{6}{|c|}{ a. Domestik } \\
\hline & Kode C & 32 & 38 & 44 & 53 \\
\hline & Kode E & 1 & 1 & 3 & 4 \\
\hline \multicolumn{6}{|c|}{ b. Internasional } \\
\hline & Kode C & 4 & 7 & 16 & 20 \\
\hline & Kode E & - & 1 & 1 & 1 \\
\hline
\end{tabular}




\begin{tabular}{ccccl} 
Total & 37 & 47 & 64 & 78 \\
Runway 03-21 L & $3.500 \mathrm{~m}$ & $3.500 \mathrm{~m}$ & $3.500 \mathrm{~m}$ & $3.500 \mathrm{~m}$ \\
Runway 03-21 R (Runway Baru) & - & - & $3.500 \mathrm{~m}$ & $3.500 \mathrm{~m}$ \\
\hline
\end{tabular}

Sumber: PT. Angkasa Pura 1

Tren peningkatan jumlah penumpang, pesawat, dan kargo memicu bandar udara internasional Sultan Hasanuddin menjadi sesak dan sudah melebihi kapasitas. Pertumbuhan penumpang, pesawat dan kargo yang pesat tersebut, maka akan dilakukan pengembangan dengan menerapkan konsep airport city yang terintegrasi dalam suatu tatanan transportasi komprehensif dan multi moda [4][10][11][12] (lihat Gambar 3).
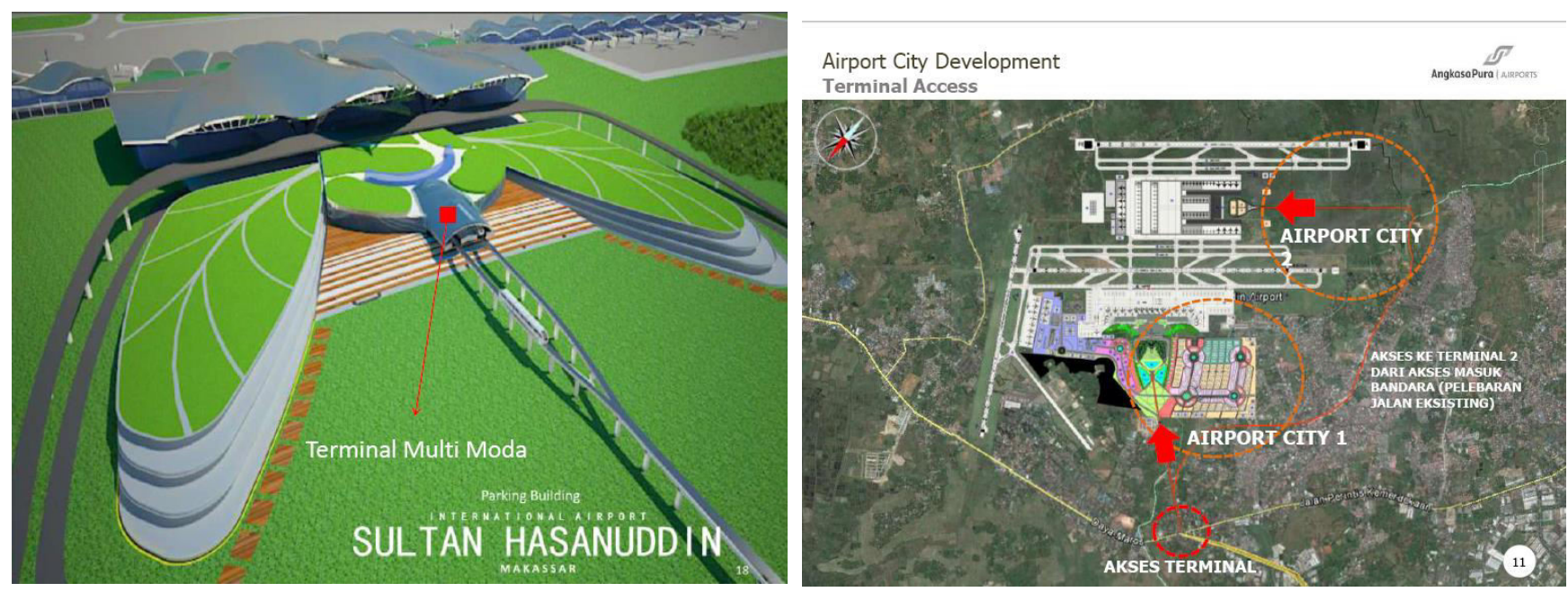

Gambar 3 (a) dan (b) Rencana Pengembangan Bandar Udara Internasional Sultan Hasanuddin menuju Airport City Development Sumber: PT. Angkasa Pura 1

Tren pertumbuhan penumpang, pesawat dan kargo ini tentunya akan menghadapi kendala dalam hal pembiayaan pengembangan konsep airport city ini dikarenakan oleh dana Pemerintah tidak mencukupi hanya dengan mengandalkan dana APBN dan APBD, sehingga perlu mengundang investor untuk berpartisipasi.

Untuk menuju konsep airport city dibutuhkan lahan seluas minimal 2.000 hektare. Saat ini hanya 900 hektare lahan. Tahap pertama akan dilakukan pembebasan lahan seluas 60 hektare dengan anggaran Rp 478 miliar. Lahan ini diperuntukkan untuk pembangunan terminal penumpang dan penambahan runway. Total investasi yang dibutuhkan airport city mencapai Rp 12 triliun, nantinya akan dilengkapi kawasan industri, perhotelan, rumah sakit, convention exhibition, shopping area, theme park dan finance area yang saling terintegrasi, komprehensif dan multi moda (kereta api, BRT, dan angkutan publik lainnya)[13][14][15].

- Rencana ekspansi ultimate Bandara Hasanuddin ditargetkan mampu menampung 45 juta-50 juta penumpang per tahun hingga 2030 dengan penambahan runway dan terminal baru [9].

Ke depan diharapkan dengan dikembangkannya Bandara Sultan Hasanuddin menuju airport city bisa terwujud 'the centre of airport city' di Indonesia, mengingat daratan Sulawesi Selatan dengan Makassar sebagai pusat pertumbuhan pembangunannya, terletak pada lokasi tengah (lokasi sentral) dilihat dari konstelasi wilayah Nusantara Indonesia secara menyeluruh dan Makassar sebagai simpul jasa distribusi yang terletak diujung (lokasi ujung) daratan Sulawesi Selatan atau Pulau Sulawesi dan juga Indonesia akan menjadi bagian dari TPP (Trans Pacific Partnership), sehingga diharapkan rute penerbangan ke dan dari bandara Sultan Hasanuddin semakin berkembang dan lancar [9][14][15].

Rencana induk pengembangan bandar udara internasional Sultan Hasanuddi menuju Airport City dengan model pengembangan berdasar BKK dan KKOP dapat dilihat pada Gambar 4. 


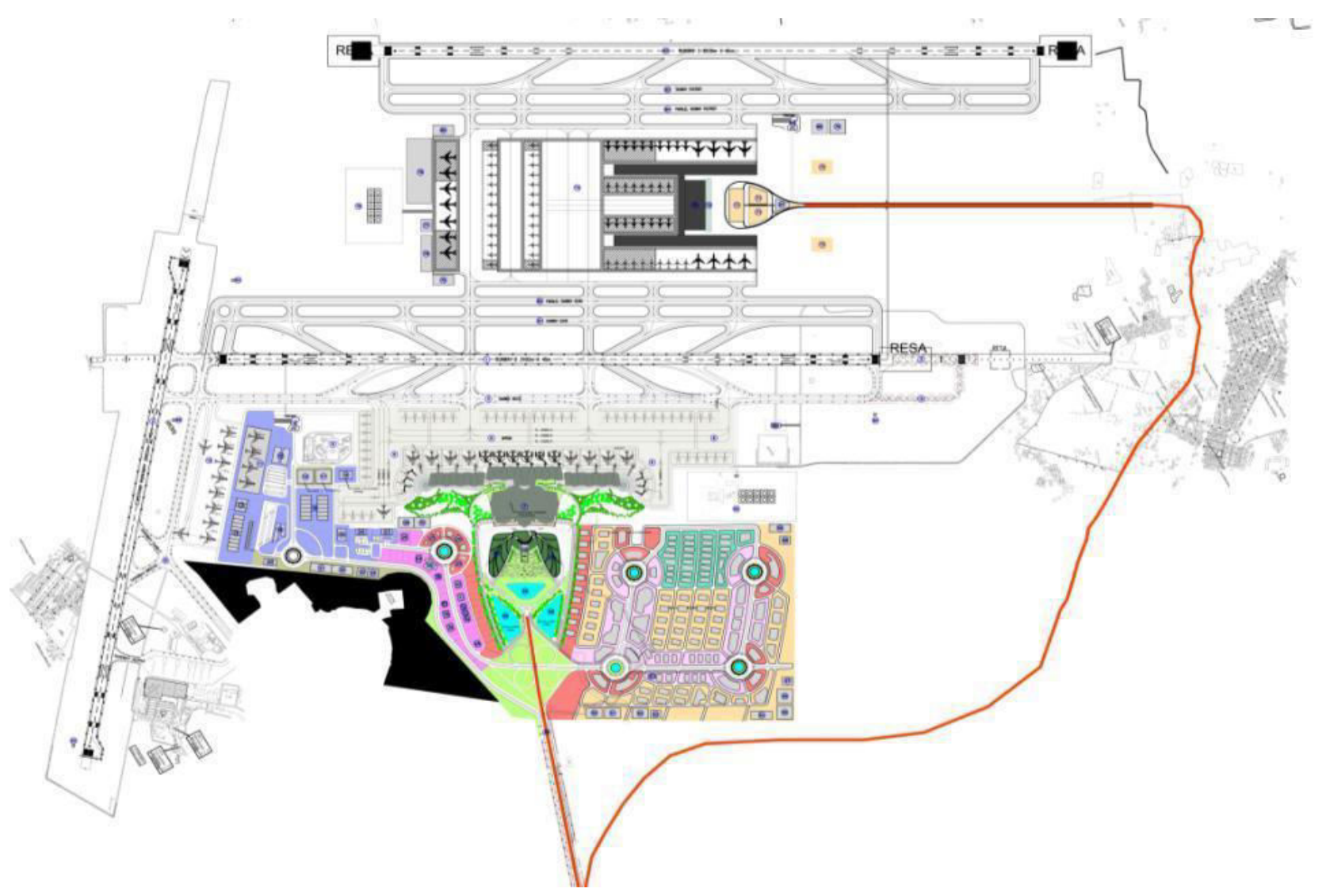

Gambar 4 Sultan Hasanuddin Airport City Development

Sumber: PT. Angkasa Pura 1

Dalam mewujudkan pembangunan Airport City pada bandar udara internasional Sultan Hasanuddin perhatiannya tidak hanya pada aspek teknis saja, tetapi juga pada aspek hukum, aspek politik, aspek ekonomi dan finansial, koordinasi dan komunikasi antar stakeholder, dan lainnya. Dalam hal percepatan pembangunan infrastruktur bandar udara dan fasilitas komersialnya tersebut tidak dapat dipungkiri bahwa salah satu permasalahan yang selalu timbul adalah dalam hal pengadaan tanah/pembebasan lahan yang sering kali prosesnya berlarut-larut sehingga tak dapat dipastikan kapan lahan dapat dibebaskan, perlu ada kepastian terhadap ketersediaan lahan agar tidak ada lagi pemunduran jadwal penyelesaian proyek. Selain masalah pembebasan lahan, tidak kalah pentingnya adalah skema pembiayaan infrastuktur bandar udara, stabilitas politik dan perekonomian guna menjamin kepastian dalam berusaha, kebijakan pemerintah, dan kemudahan dalam perizinan [16].

Dalam rangka pengembangan konsep airport city pada bandar udara internasional Sultan Hasanuddin sebagai airport city yang pertama di Indonesia maka sebagai studi kasus perlu dibandingkan dengan studi kasus yang terjadi di negara lain yang telah berhasil menerapkan konsep airport city ini, sehingga dapat memberikan gambaran yang lebih jelas tentang sistem kebandarudaraan secara komprehensif. Dengan pembahasan tentang konsep airport city ini, maka diharapkan menjadi bahan pembelajaran / diskusi untuk selanjutnya melakukan langkah-langkah yang lebih terencana, efektif dan efisien untuk pengembangan sub sektor transportasi udara yang terintegrasi antar moda dan multi moda dengan sub sektor transportasi lainnya baik darat, laut dan kereta api.

\section{Studi Kasus pada Beberapa Airport City di Dunia}

Beberapa kota/negara yang telah sukses menerapkan konsep airport city dan aerotropolis, diantaranya Amsterdam, Netherlands (Schipol Airport); Dallas (Worth Airport); California (Ontario Airport); Detroit 
(Pinnacle Airport); Campinas, Brazil (Viracopos Airport); Hongkong (Hongkong International Airport); Philippines (Subic Bay Airport); Seoul, Korea (Incheon International Airport), dan airport city lainnya.

Schipol dilengkapi dengan shopping arcades, restaurants, hotel, internet cafes, office building, cargo city, dan memperkerjakan 58.000 tenaga dalam lingkungan airport. Hongkong dilengkapi dengan logistics, office/retail, entertainment/exhibition, shopping mall terkoneksi secara multimoda dan memperkerjakan 45.000 tenaga kerja. Incheon dilengkapi dengan international business (trade and finance center, office building, telecom center, exhibition center, convention center), industri dan logistik (aircraft industry, high-tech R \& D, multimedia/information, e-commerce, distribution center), tourism (hotel, condominium, shopping mall, tourist districts, museum, aquarium, golf course, marina), residential dan lainnya (town house, flat, international school, hospital, administration complex). California dilengkapi dengan multimodal logistics, intermodal rail, interstate highways, logistics dan distribution space dan urban complex. Detroit dilengkapi dengan aviation-themed environment, integrates open space dan active recreation, office, technology, light-industrial dan retail development[5][6]. Beberapa Airport City di dunia dapat dilihat pada Gambar 5.

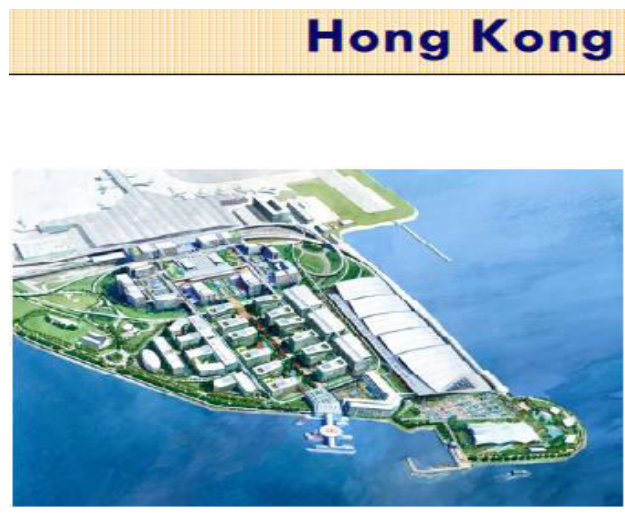

Detroit's New Image-Builder

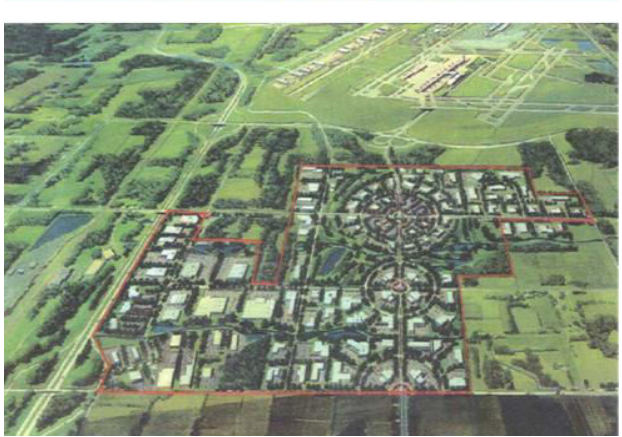

\section{Incheon International Airport} (Seoul, Korea)

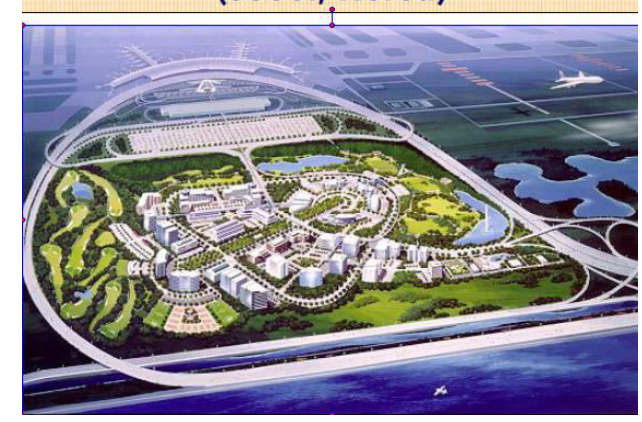

\section{Ontario, California}

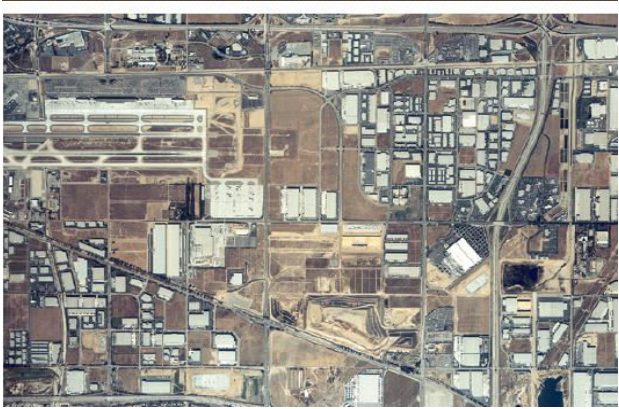

Gambar 5 (a), (b), (c), dan (d) Beberapa Airport City di Dunia

Sumber: New Urban Development at and around Airports [6]

\section{Kesimpulan}

Sebagai kata kunci dapat disebutkan bahwa: (1) dunia penerbangan dan bandar udara ke depan menjadi pusat pengembangan ekonomi dan bisnis yang kompetititf, (2) sekitar 40\% nilai perdagangan dunia melalui lalu lintas udara, (3) fasilitas komersial dengan cepat menghubungkan dengan pasar (markets), (4) perdagangan (air commerce) terhubung dengan airport city dan aerotropolis, dan (5) airport sebagai penggerak utama bisnis dan pengembangan kota di abad 21 ini (21st century). 


\section{Daftar Pustaka}

[1] S. A. Adisasmita, Tatanan Bandar Udara Nasional. Yogyakarta: Graha Ilmu, 2014.

[2] S. A. Adisasmita, Mega City dan Mega Airport. Yogyakarta.: Graha Ilmu, 2013.

[3] S. A. Adisasmita, Penerbangan dan Bandar Udara. Yogyakarta: Graha Ilmu, 2012.

[4] S. A. Adisasmita, Perencanaan Infrastruktur Transportasi Wilayah. Yogyakarta: Graha Ilmu, 2012.

[5] D. F. Goldberg, Attributes of Successful Airport City Development Programs. Landrum \& Brown., 2012.

[6] D. Kasarda, J, New Urban Development At And Around Airports. The University of North Carolina, 2006.

[7] N. Ashford and P. H. Wright, Airport Engineering (3rd ed). New York: A Wiley-Interscience Publication, 1992.

[8] PT Angkasa Pura I, "Bandara Internasional Sultan Hasanuddin Makassar,” 2016.

[9] PT Angkasa Pura I, "Website Bandar Udara.".

[10] S. A. Adisasmita, Transportasi Komprehensif dan Multi Moda. Yogyakarta: Graha Ilmu, 2014.

[11] S. A. Adisasmita, Transportasi dan Pengembangan Wilayah. Yogyakarta: Graha Ilmu, 2011.

[12] S. A. Adisasmita, Jaringan Transportasi: Teori dan Analisis. Yogyakarta: Graha Ilmu, 2011.

[13] S. A. Adisasmita, Perencanaan dan Pembangunan Transportasi. Yogyakarta: Graha Ilmu, 2011.

[14] Dinas Perhubungan Sulawesi Selatan, "Rencana Pembangunan Perkeretaapin Provinsi Sulawesi Selatan," 2015.

[15] Pelindo 4, "Pembangunan Makassar New Port," 2016.

[16] S. Priatna, Pengadaan Tanah Dalam Upaya Mendukung Percepatan Pembangunan Infrastruktur. Buletin Tata Ruang dan Pertanahan, 2011.

Use the "Insert Citation" button to add citations to this document.

[17] Adisasmita, S.A., 2016. Perencanaan Sistem Transportasi Publik. Graha Ilmu, Yogyakarta. 